\title{
From Drone-Based Remote Sensing to Digital Outcrop Modeling: Integrated Workflow for Quantitative Outcrop Interpretation
}

\section{Mokhles M Mezghani ${ }^{\star}$, Mohammed I Fallatah and AbdulJaleel A AbuBshait}

Department Advanced Research Center, Saudi Aramco, Dhahran, Saudi Arabia

*Corresponding author: Mokhles M Mezghani, Department Advanced Research Center, Saudi Aramco, Dhahran, Saudi Arabia, Tel: +966 13 873-7969; E-mail: mokhles.mezghani@aramco.com

Rec date: April 03, 2018; Acc date: April 17, 2018; Pub date: April 20, 2018

Copyright: (c) 2018 Mezghani MM, et al. This is an open-access article distributed under the terms of the Creative Commons Attribution License, which permits unrestricted use, distribution, and reproduction in any medium, provided the original author and source are credited.

\begin{abstract}
Oil and gas exploration applies numerical modeling techniques to understand the development of hydrocarbonbearing basins and to provide quantitative subsurface models. The accuracy of any prediction depends on several factors, such as the modeling approach, data acquisition, and data interpretation. Unfortunately, in the oil and gas industry the quantity of reliable data available to build models is very limited compared to the size of sedimentary basins.

Outcrops are valuable sources of information that should be used to characterize the subsurface. Unfortunately, we are far from achieving the objective of fully benefiting from outcrops. Despite the fact that an outcrop is directly accessible, its quantitative modeling and integration remain an issue. Usually, we organize field trips where several experienced geologists are involved to collect descriptive data from outcrops, which include rock samples, measured sections, and photos. The outcomes from these field trips are mainly conceptual and qualitative models of the surface geology without any quantitative impact on the subsurface modeling and characterization workflows. Moreover, accessibility to cliffs or canyons in any outcrop is a major safety obstacle when conducting field trips.

The main goal of this work is to investigate and develop new technologies for high resolution $3 D$ outcrop modeling ( $\mathrm{cm}$ to $\mathrm{mm}$ scale). High resolution outcrop models will constitute a virtual dataset that a geologist can visit at any time from his desktop. The proposed solution for this challenge is to develop an integrated workflow for remote geological assessment based on drones and remote sensing technologies. The general workflow starts with the selection of an area of interest using any geographic information system (GIS) to plan the flight route of the unmanned aerial vehicle (UAV). This is then followed by selection of the model type, for instance digital elevation, texture, and/or mineral composition as well as the required resolution. After acquiring the data using drones equipped with the appropriate sensors, we proceed to data processing, where the acquired data is converted to geological models that geologists can use to study the outcrop. Finally, general-purpose software is used for outcrop model visualization. This workflow was successfully applied to the Wadi Dirab outcrop in Central Saudi Arabia.
\end{abstract}

Keywords: Geology; Drone; Remote sensing; Geographic information system

\section{Introduction}

Oil and gas exploration applies numerical modeling techniques to understand the development of hydrocarbon-bearing basins and to provide quantitative subsurface models. The accuracy of any prediction depends on several factors such as the modeling approach, data acquisition, and data interpretation. Unfortunately, in the oil and gas industry, the quantity of reliable data available to build models is limited compared to the size of sedimentary basins. Indeed, only cores collected from relatively few exploration and development wells provide direct and quantitative subsurface information. In contrast, sedimentary rocks outcrops, by their areal coverage and direct accessibility to geologists, provide excellent analogues to the subsurface that should be quantitatively integrated to the reservoir characterization and modeling workflow.

Outcrops are valuable sources of information that should be used to characterize the subsurface. Unfortunately, we are far from achieving the objective of fully benefiting from outcrops. Indeed, despite the fact that an outcrop is directly accessible, its quantitative modeling and integration remain an issue. We usually organize field trips where several experienced geologists are involved, to collect descriptive data from outcrops, which include rock samples, measured sections, and photos. The outcomes from these field trips are mainly conceptual and qualitative models of the surface geology without any quantitative impact on the subsurface modeling and characterization workflows. Moreover, accessibility to cliffs or canyons in any outcrop is a major safety obstacle when conducting field trips.

The main goal of this work is to investigate alternative technologies for high resolution $3 \mathrm{D}$ outcrop modeling ( $\mathrm{cm}$ to $\mathrm{mm}$ scale). High resolution outcrop models will constitute a virtual dataset that a geologist can visit at any time from his desktop, and extract in realtime any piece of information/data needed. These could then be easily integrated in the subsurface modeling workflow to enhance characterization and reduce uncertainties. The proposed solution for this challenge is to develop an integrated workflow for remote geological assessment based on drones and remote sensing technologies.

The general workflow starts with the selection of an area of interest using any geographic information system (GIS) to plan the flight route 
of the unmanned aerial vehicle (UAV). This is then followed by selection of the model type, for instance digital elevation, texture, and/or mineral composition as well as the required resolution. This information is needed to select suitable sensors and drones for the data acquisition. After acquiring the data using drones equipped with the appropriate sensors, we proceed to data processing, where the acquired data is converted to geological models that geologists can use to study the outcrop. The need for millimeter-scale resolution requires intensive computational resources to be able to process large data volumes in reasonable amounts of time.

Finally, general-purpose software is used for outcrop model visualization. In addition, specific tools can be developed for geoscientists to facilitate the interaction between the geologists and the virtual outcrop, e.g., for horizon picking, or core extraction. This workflow was successfully applied to the Wadi Dirab outcrop in central Saudi Arabia. Multiple models were generated with resolutions ranging from $2 \mathrm{~cm}$ (as a baseline resolution) to $1 \mathrm{~mm}$ (for targeted locations/ measured sections). Such high-resolution outcrop models are a key step in providing analogues for subsurface reservoirs that will consolidate our understanding of their vertical and lateral heterogeneities as well as facies architecture within them. Although this new workflow still has to be validated and can be fundamentally improved, it already demonstrated its usefulness for geological outcrop documentation and modelling in remote areas.

\section{Materials and Methods}

\section{Wadi dirab: The hanifa formation}

The economic conventional hydrocarbon accumulations found within the Hanifa Formation, as well as its potential for unconventional plays, make it one of the important Jurassic units in Saudi Arabia. Therefore, a comprehensive understanding of the Hanifa Formation surface geology could provide real 3-D analogues for the reservoir in the subsurface. Such analogues would provide information about the depositional facies and their vertical and lateral relationships, which in turn will help address facies architecture and flow units when constructing reservoir models for simulation.

Recent work by Fallatah and Kerans [1] examined the Hanifa Formation at a regional scale at its exposure in the Tuwaiq Mountains in Central Arabia (Figure 1). The study detailed the sedimentology and stratigraphy of the formation and recognized areas that have exposures of reservoir facies. One of these areas is Wadi Dirab, where the complete section of the Hanifa Formation with its contacts with underlying and overlying formations is exposed.

The Hanifa is preceded by the Tuwaiq Mountain Limestone and succeeded by the Jubaila Formation (Figure 2). Hughes et al. [2] recognized the basal contact with the Tuwaiq Mountain Limestone as a paraconformity surface whereas a disconformity was recognized for the upper contact with the Jubaila Formation. Based on the ammonite Euaspidoceras perarmatum identified in the lower member of the formation, Hawtah, the Hanifa Formation is assigned to Oxfordian age $[3,4]$.

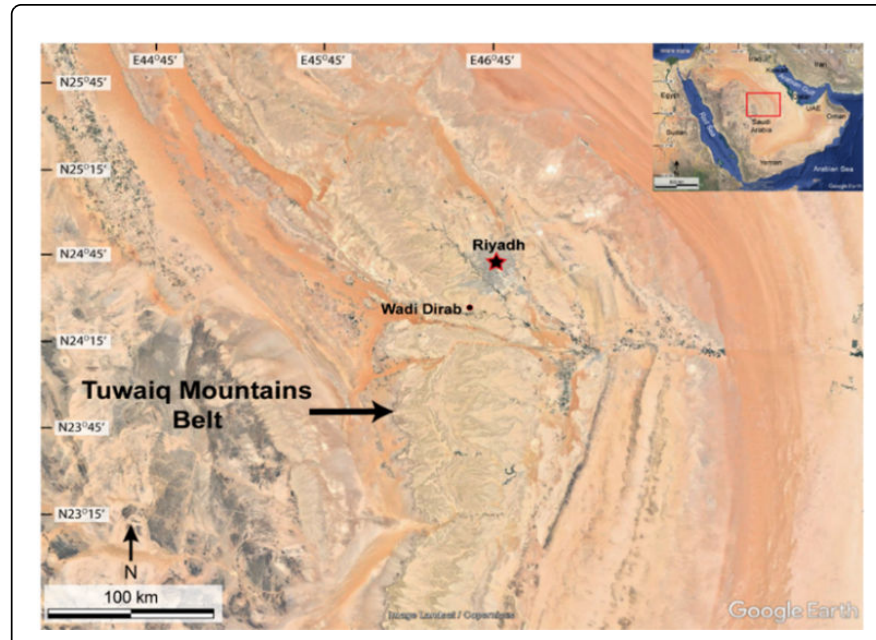

Figure 1: Google Earth image showing the study area (modified after Fallatah and Kerans, 2018).

In contrast, the presence of echinoderm species Pygurus smelthei and Polycyphus parvituberculatus found in the upper Ulayyah Member of the Hanifa, the top of the formation is assigned to Late Oxfordian-Early Kimmeridgian age [4]. The lateral extension of Wadi Dirab outcrop $\left(5,000,000 \mathrm{~m}^{2}\right)$, the thickness of the Hanifa formation $(113 \mathrm{~m})$, the number of needed measured sections $(7$ measured sections), and the risk associated with difficult access to most of the outcrop made this location an excellent candidate to test and validate this new workflow combining drone-based remote sensing and digital photogrammetry (Figures 3 and 4 ).

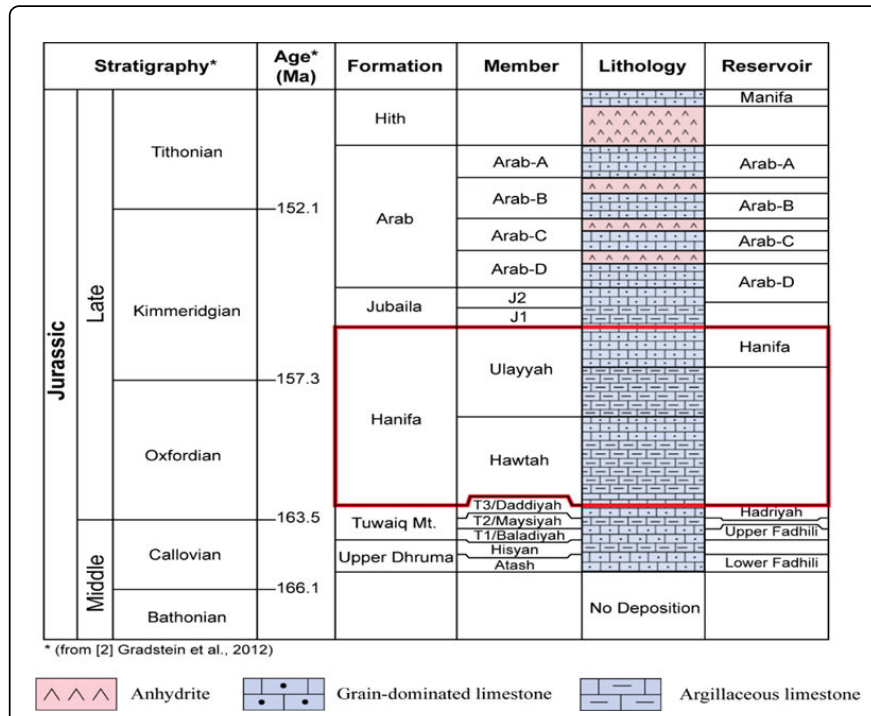

Figure 2: Stratigraphy of the Late Jurassic of central Saudi Arabia. The time scale of Gradstein et al. [5] is used for stratigraphic ages (modified after Hughes [6]). 
Citation: Mezghani MM, Fallatah MI, Abubshait AA (2018) From Drone-Based Remote Sensing to Digital Outcrop Modeling: Integrated Workflow for Quantitative Outcrop Interpretation. J Remote Sensing \& GIS 7: 237. doi:10.4172/2469-4134.1000237

Page 3 of 7

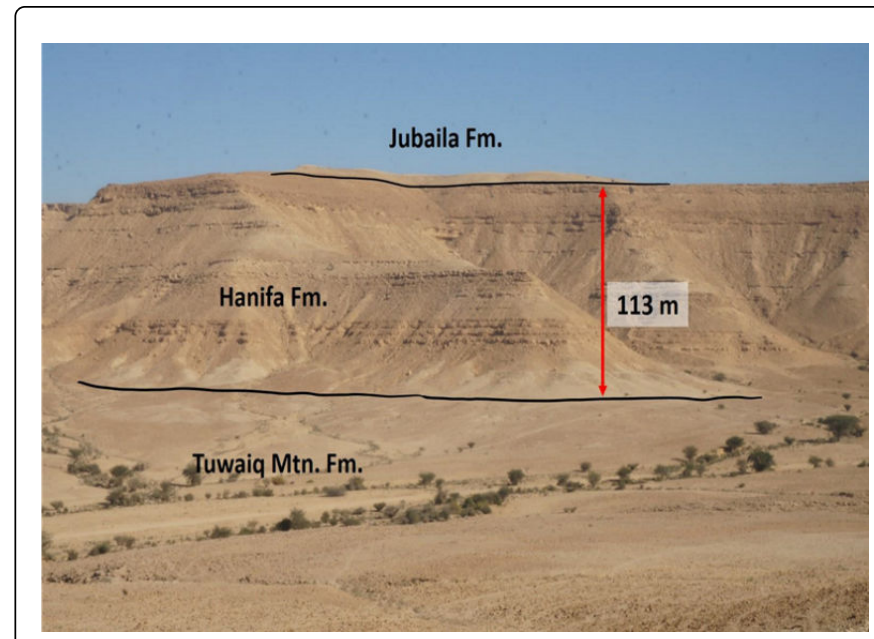

Figure 3: Wadi Dirab outcrop overview-Tuwaiq, Hanifa, Jubaila Formations.

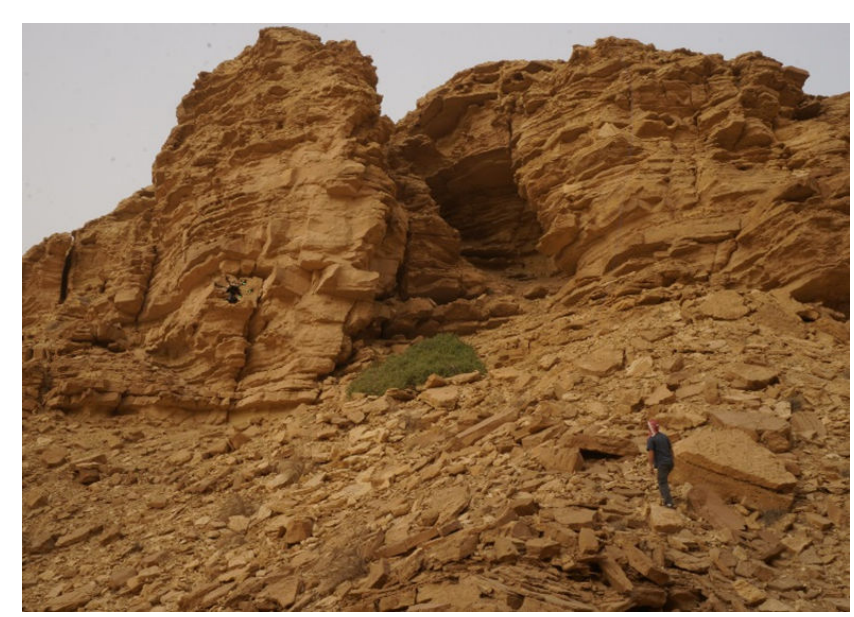

Figure 4: Wadi Dirab outcrop overview-Unsafe working environment.

\section{Digital photogrammetry}

Photogrammetry is the "art, science and technology of obtaining reliable information about physical objects and the environment through the process of recording, measuring and interpreting photographic images and patterns of electromagnetic radiant imagery and other phenomena" (American Society of Photogrammetry and Remote Sensing [7]).

Photogrammetry was first introduced in 1851 by Colonel Aimé Laussedat [8], but it was not until almost 60 years later that the technique was successfully employed during World War I. Over time, the development of photogrammetry has passed through the phases of plane table photogrammetry (Figure 5), analog photogrammetry, analytical photogrammetry, digital photogrammetry, and has now entered the phase of high-resolution digital photogrammetry with the advent of high-resolution cameras, remote sensing technology, unmanned air vehicles (drones), as well as supercomputers to process the acquired digital images in parallel mode.

Digital photogrammetry (close-range and aerial) is applied to digital images that can be scanned from existing paper photographs or directly captured by digital cameras. The output products are models in digital form, such as digital maps, digital elevation models (DEM), digital ortho-images, and textural models (Figure 6).

The mathematical background behind digital photogrammetry has been well-established through different techniques, for instance, image registration, image processing, and triangulation. The development of new algorithms based on emerging computing hardware (parallel computing, GPUs, etc.) is highly needed. Several programs exist to automate the complex tasks associated with "non-digital" photogrammetry, and to easily handle the huge amount of data acquired with high-resolution cameras mounted on drones.

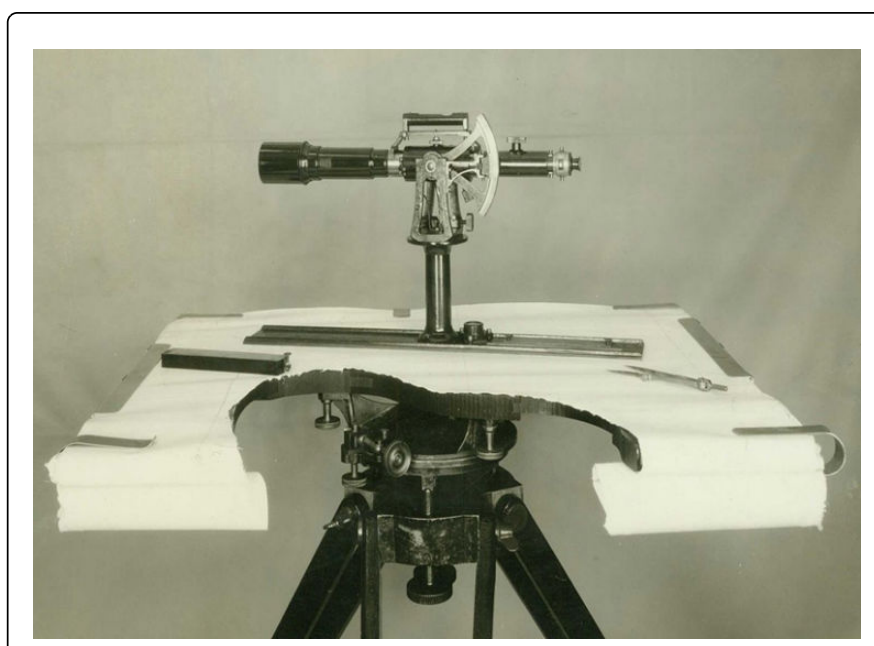

Figure 5: A plane table with part of the surface of the table cut away to show the mounting on the tripod.

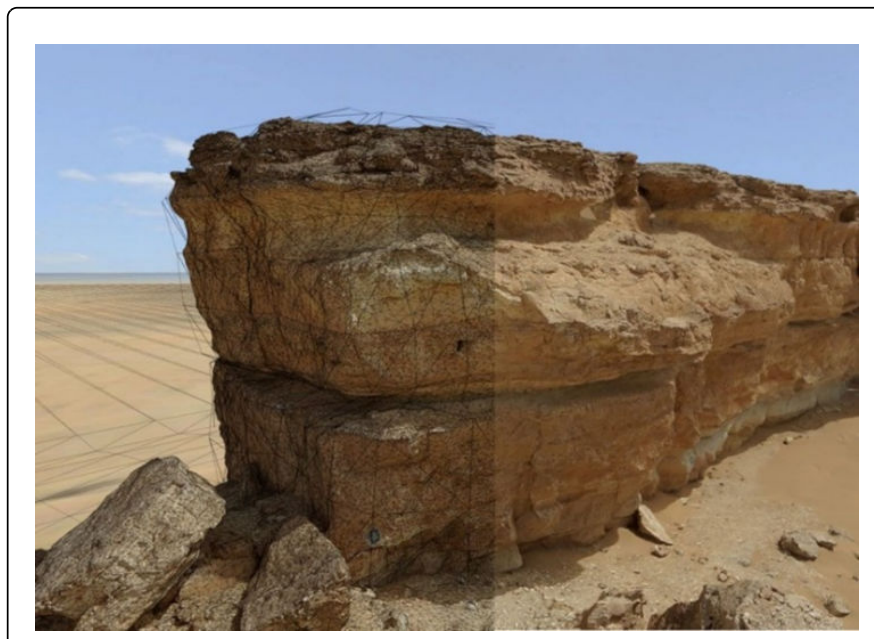

Figure 6: Outcrop digital model using digital photogrammetry. 


\section{Drone-based digital photogrammetry}

The development of drones was primarily driven by military needs such as for inspection, surveillance, and mapping. In recent years, drones have been widely used in many civil disciplines, such as geology, geography, ecology, archaeology, and many others. The quick development of civilian solutions was made possible by the decreased cost of such technology, as well as the spread and improvement of digital cameras and GPS systems, which are necessary for navigation and geo-referencing tasks.

In geology, drones are a safe and low cost alternative to traditional field work where several geologists are involved to collect descriptive data from outcrops, for example, rock samples, measured sections, and photos. Safety requirements and regulations for oil and gas companies have made drone-based photogrammetry a very attractive alternative to conventional field work, e.g., outcrop accessibility to cliffs or canyons is a major obstacle when conducting field trips.

Drones can be classified in many different ways based on shape, size, range, weight, purpose, etc. The most important classes of drones are the multi-copters (rotary-wings (Figure 7)) and fixed-wings (Figure 8). Although both classes are widely used in photogrammetric surveys, both have their unique advantages and drawbacks. There is also a wide price range depending on their capability to perform autonomous flights, flight time, payload, automation capabilities, and so forth. Lowcost solutions do not allow a completely autonomous flight, and in most cases, they require human assistance for take-off and landing. In contrast, high-cost solutions allow safe landing options, mitigating risks of the drone getting damaged during landing. The characteristics of these two types are drones are listed below:

Multi-copters: Consist of rotorcraft with more than two propellers fixed to a structure. The position and motion of the drone are controlled by managing the differential engine rotation speed of any single propeller. This type of system is very flexible in relation to the various different tasks and payloads. Multi-copters are preferred very often because of their high maneuverability, small dimensions, short deployment time and high stability. Batteries do not have a very long life (30 minutes maximum; depending on the load, flight conditions, etc.), which means batteries must be changed for missions requiring long sessions of flight.

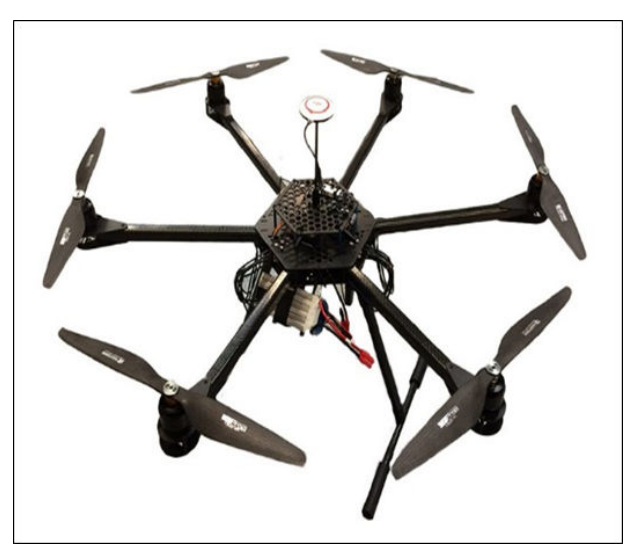

Figure 7: Multi-copters drone.

Fixed-wings: are designed like traditional aircraft and look similar to an airplane. They are equipped with one or more propellers that are not producing direct vertical liftoff force, and per consequence, fly in a straight direction. Most of these drones require a huge open space to takeoff and work in a fully autonomous mode following a pre-planned flight plan. The characteristics of this design make the drones suitable for aerial photogrammetry, due to their high autonomy and possibility of covering wider areas than multi-copters.

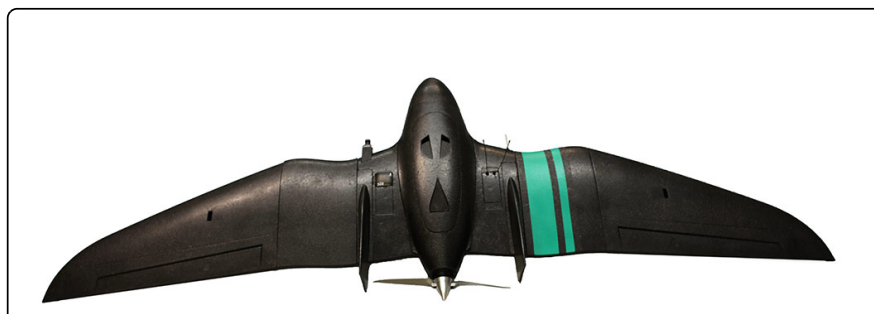

Figure 8: Fixed-wing drone.

Drone-based photogrammetry is an aerial survey method that combines drones with aerial photogrammetry. It involves mounting a digital camera on a drone platform (multi-copters and fixed-wings can be combined). The benefits of using drones for photogrammetric surveying are the work efficiency (execution speed), providing access to inaccessible zones by geologists, such as cliffs and canyons, improved safety (virtual outcrop), and cost effectiveness. Due to all these advantages, multiple potential outcrops can be scanned, rather than focusing all the geologist efforts on a single accessible location. Furthermore, more measured sections can be achieved with highresolution quality by adopting multi-copters with close-range photogrammetry, which simply cannot be achieved by traditional means alone, or by terrestrial surveying.

\section{Wadi dirab drone-based photogrammetry challenge}

Area of interest: The goal of this challenge was to acquire high resolution scans (cm-scale resolution) of Wadi Dirab outcrop (approximately 5,000,000 $\mathrm{m}^{2}$ ) in a much more comprehensive and time-saving manner by using drone-based photogrammetry compared to traditional geological surveying.

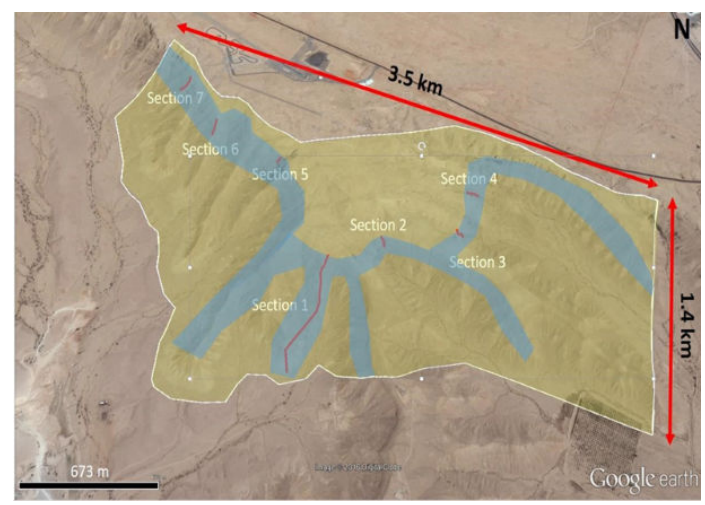

Figure 9: Wadi Dirab outcrop overview: Area of interest covering 5 $\mathrm{km}^{2}$ and seven measured sections location. 
Citation: Mezghani MM, Fallatah MI, Abubshait AA (2018) From Drone-Based Remote Sensing to Digital Outcrop Modeling: Integrated Workflow for Quantitative Outcrop Interpretation. J Remote Sensing \& GIS 7: 237. doi:10.4172/2469-4134.1000237

Page 5 of 7

Seven measured sections were defined to be scanned at much higher resolution (mm-scale resolution). The area of interest, shown in Figure 9 , is limited by the white boundary. The area in yellow is scanned by the fixed-wing drone (areas not requiring oblique capture). The area in blue represents the upper saddles of the outcrop vertical sections (areas requiring detailed oblique captures by the hexa-copters). The thin red lines within the blue areas represent the seven measured sections scanned at a close range using the hexa-copters. A more detailed description of the data acquisition phase is provided in the subsequent section). A global view of the outcrop is shown in Figures 10-12.

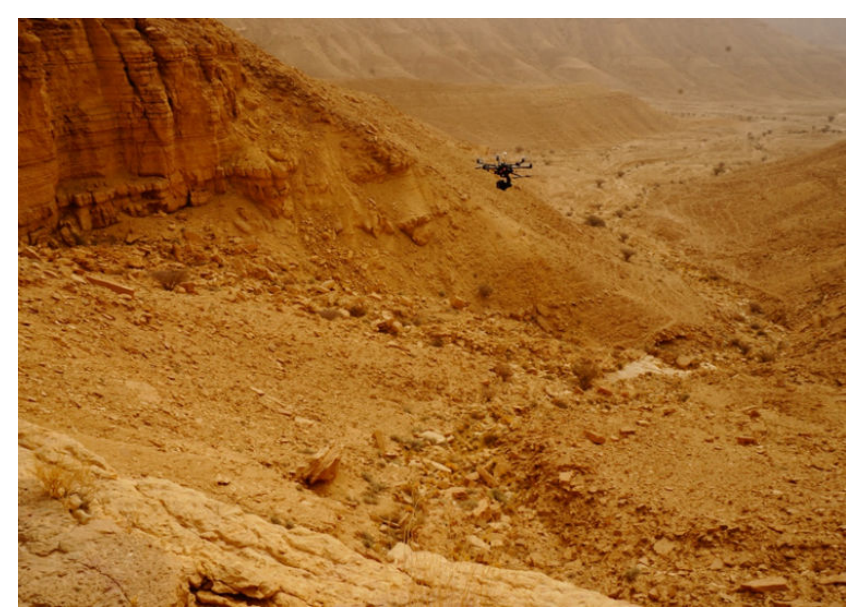

Figure 10: Wadi Dirab outcrop overview: Global view 1 showing the hexa-copters drone in action taking the high resolution images.

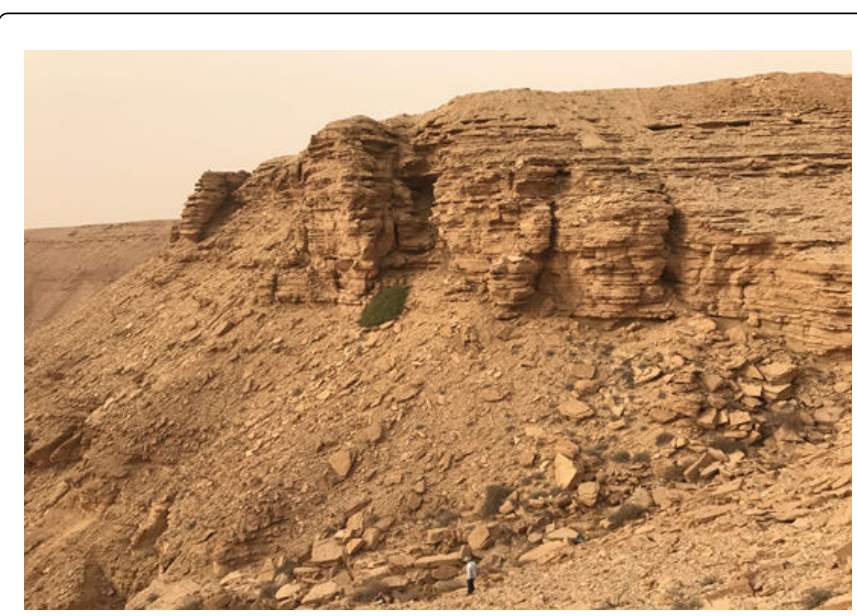

Figure 11: Wadi Dirab outcrop overview: Global view 2 illustrating the safety and technical challenges to conducting conventional field work.

Data acquisition: The drones were each equipped with a $100 \mathrm{~mm}$ focal length lens and configured for vertical measurement mode. Multi-scale scanning was adopted to cover this large outcrop. First, general top-down scans using fixed-wings drones with $2.0 \mathrm{~cm}$ ground resolution were carried out for the entire outcrop (approximately $5,000,000 \mathrm{~m}^{2}$ ). Second, oblique flights with $2.0 \mathrm{~cm}$ ground resolution using hexa-copters drones captured the vertical faces along the escarpment edge of the outcrop (approximately 600,000 $\mathrm{m}^{2}$ ). Finally, a targeted scan was conducted for seven measured sections $\left(7,000 \mathrm{~m}^{2}\right)$ with $1.0 \mathrm{~mm}$ ground resolution using hexa-copters drone.

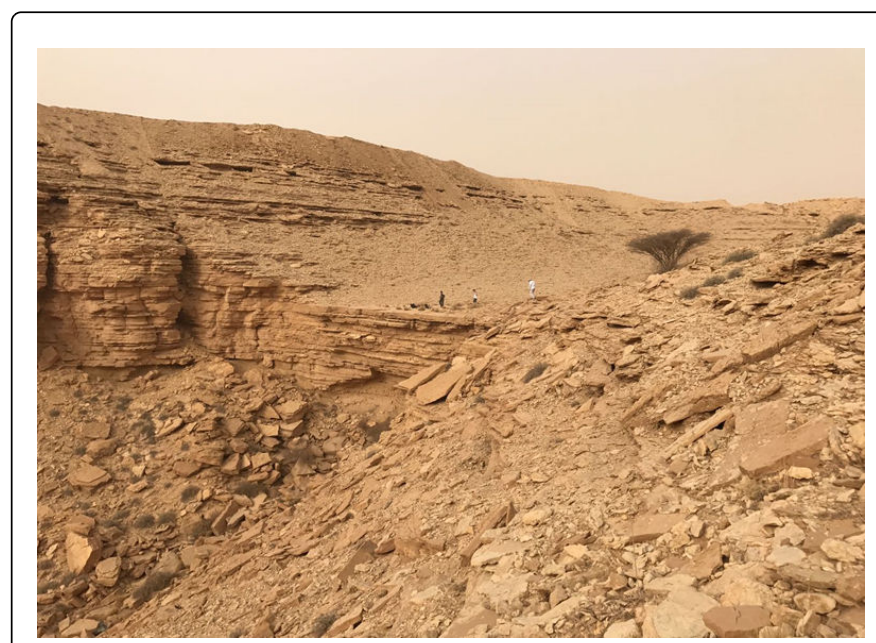

Figure 12: Wadi Dirab outcrop overview: Global view 3 illustrating the safety and technical challenges to conducting a conventional field work.

For Wadi Dirab, we employed a combination of drones (fixed-wings and multi-copters) to conduct a series of autonomous flights covering the entire area. The drones can fly only below 125 m (AGL: height Above Ground Level) to remain below civil airspace. The autonomous flights are planned in advance so that total coverage is achieved for the desired area. The entire area was scanned using the fixed-wing drones (NADIR capture). The fixed-wing drones captured the entire area at $2.0 \mathrm{~cm}$ GSD (Ground Sampling Density) providing a full 3D base map with only two flights.

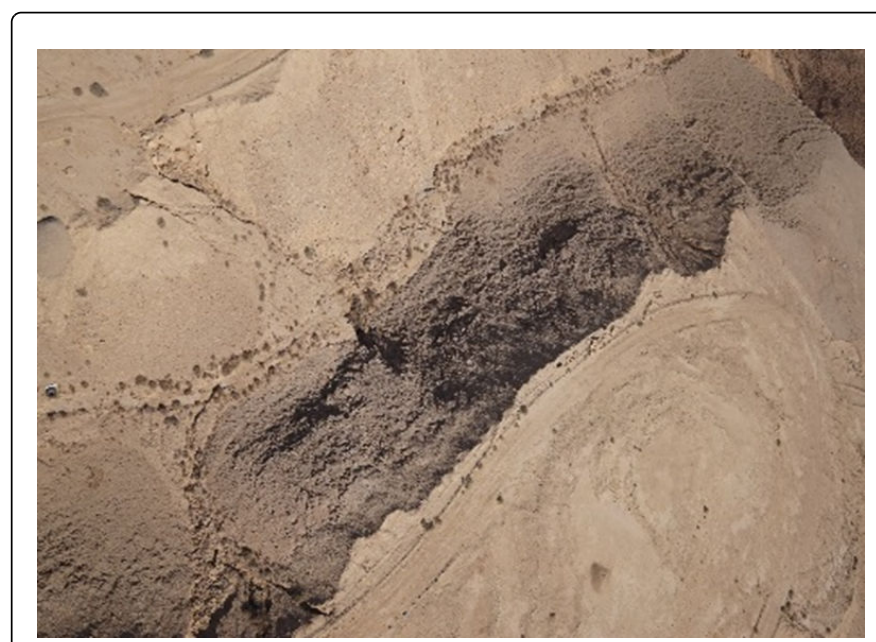

Figure 13: Image acquired by the fixed-wing drone - General topdown scan.

This base map was used as a reference for spatially locating the high resolution section scans within the 5,000,000 $\mathrm{m}^{2}$ scanned. The GCP (Ground Control Points) markers were automatically detected and integrated into the base map. For the vertical outcrop faces, hexa- 
Citation: Mezghani MM, Fallatah MI, Abubshait AA (2018) From Drone-Based Remote Sensing to Digital Outcrop Modeling: Integrated Workflow for Quantitative Outcrop Interpretation. J Remote Sensing \& GIS 7: 237. doi:10.4172/2469-4134.1000237

Page 6 of 7

copters were used due to their versatility in capturing oblique angles with high precision 50 MP (Mega Pixels) imaging sensors. The achieved GSD was $2.0 \mathrm{~cm}$ for the supporting capture topography.

For the measured sections, to achieve the desired pixel GSD of 1.0 $\mathrm{mm}$ per pixel for each outcrop section, the flight transects were designed to be no further than 7.5 meters away from the measured sections (vertical high resolution band). Up to two flights were required for each section based on their width and height (width ca. 10 $\mathrm{m}$, height range from $20 \mathrm{~m}$ to $115 \mathrm{~m}$ ). Overlap was set to 0.5 meters per image with an average image capture frequency of $800-1000$ images per flight. During this data acquisition phase, more than 500 GB of raw data and about 20,000 images were acquired and went through processing to obtain the various models. Examples of acquired images are shown in Figures 13-15.

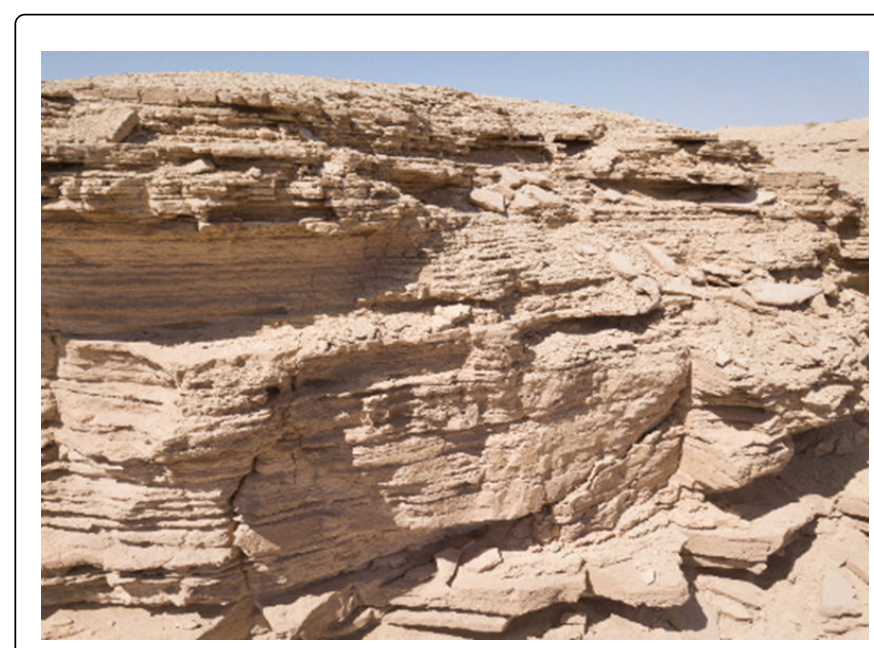

Figure 14: Image acquired by the hexa-copters drone (outcrop vertical face) with $2 \mathrm{~cm}$ ground resolution.

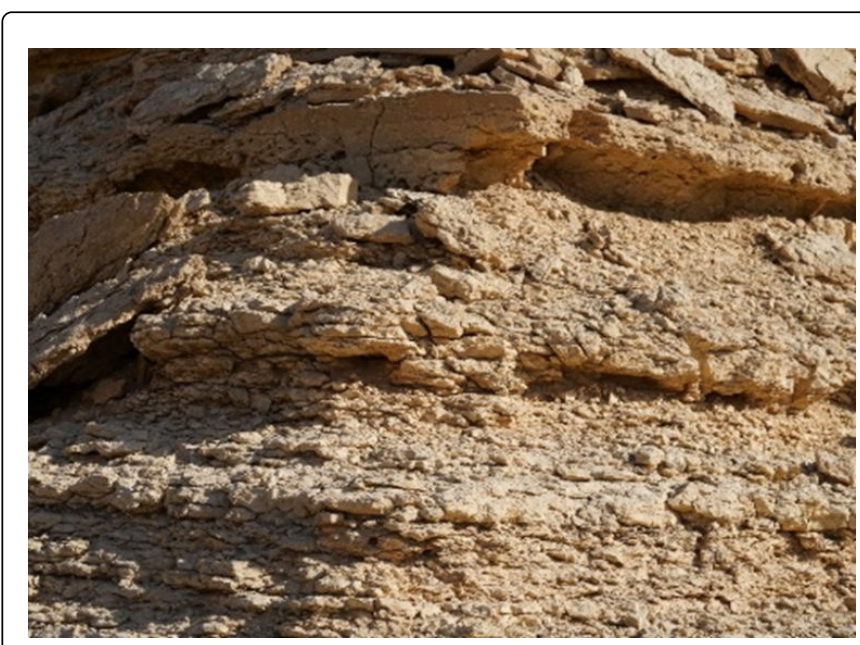

Figure 15: Image acquired by the hexa-copters drone (vertical measured section) with a ground resolution below the $\mathrm{mm}$ scale.

Modeling results: All images captured by the drones were transferred to the photogrammetry workstation cluster and processed using SfM tools (Structure for Motion) to automatically generate a dense 3D point cloud, Digital Elevation Model (DEM), 3D mesh, and ortho-rectified images. The dense 3D point cloud of the outcrop sections and the lower resolution base map survey were merged together, using SfM tools and the co-located ground control points to generate the final multiple resolution DEM integrating the high resolution measured section.

From this modeling phase, we achieved:

- 2-centimeter resolution orthophoto and DSM covering 6,000,000 $\mathrm{m}^{2}$.

- 10 -centimeter DTM covering the same $6,000,000 \mathrm{~m}^{2}$.

- $620,000 \mathrm{~m}^{2}$ of cliff-face escarpment at $2.0 \mathrm{~cm}$ resolution captured head-on to the outcrop (6 million triangles).

- Seven measured sections captured at $1.0 \mathrm{~mm}$ resolution totaling $7,000 \mathrm{~m}^{2}$ face-on to the outcrop (22 million triangles).

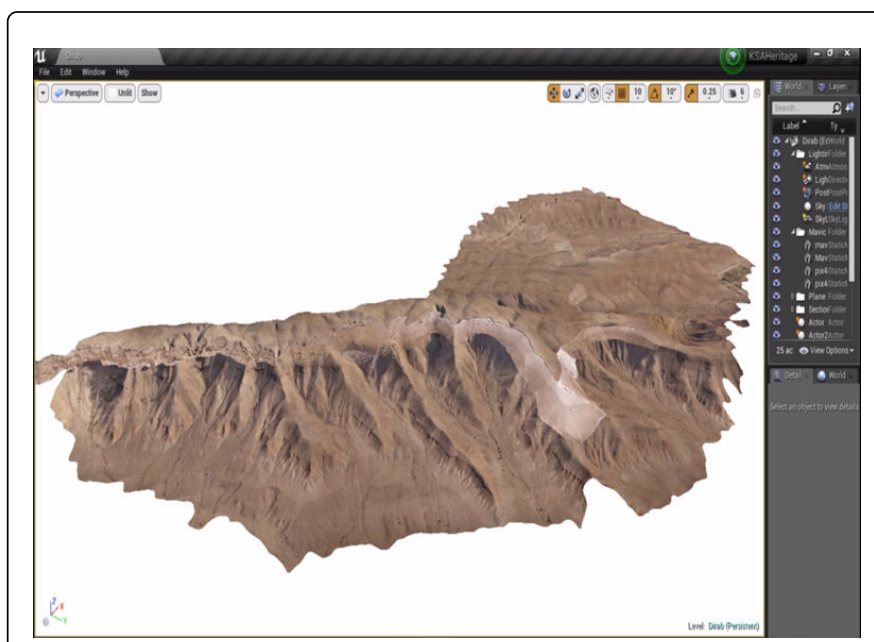

Figure 16: Digital outcrop model visualization from PC desktop using a customized version of open source gaming software.

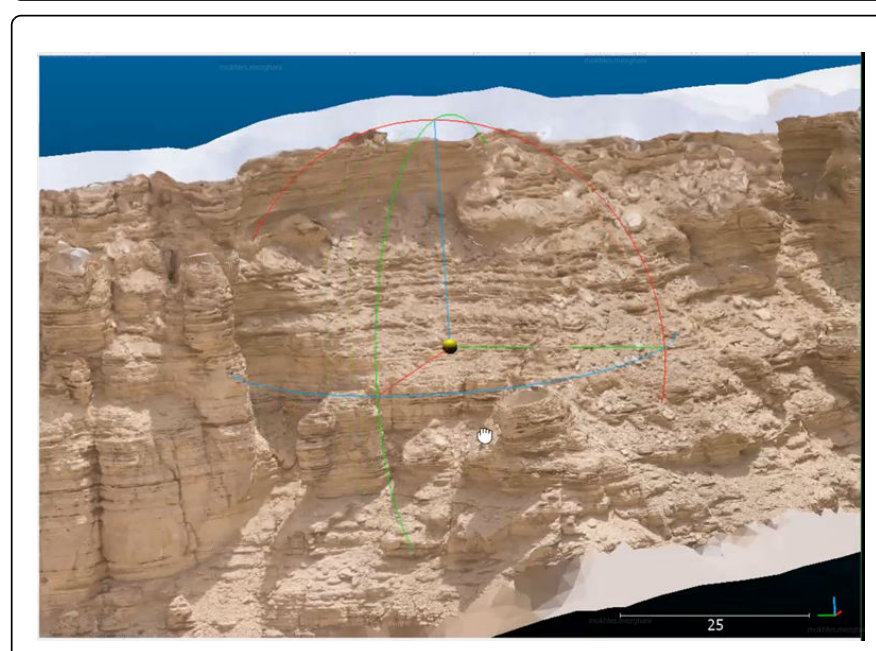

Figure 17: 3D Digital outcrop model offering visual tool for remote outcrop visualization.

With this workflow, we are able to produce photo-realistic 3D models, which can then be exported as 3D models to other 
Citation: Mezghani MM, Fallatah MI, Abubshait AA (2018) From Drone-Based Remote Sensing to Digital Outcrop Modeling: Integrated Workflow for Quantitative Outcrop Interpretation. J Remote Sensing \& GIS 7: 237. doi:10.4172/2469-4134.1000237

Page 7 of 7

professional software, for example CAD or GIS. These models can also be exported to freeware 3D imaging formats. 3D models (Figures 16-18) created on the basis of photogrammetric data provide a better understanding of spatial relationships of geological objects to geologists and allow to link different information to the model such as geological maps, geological cross-sections, and a 3D model of the territory.

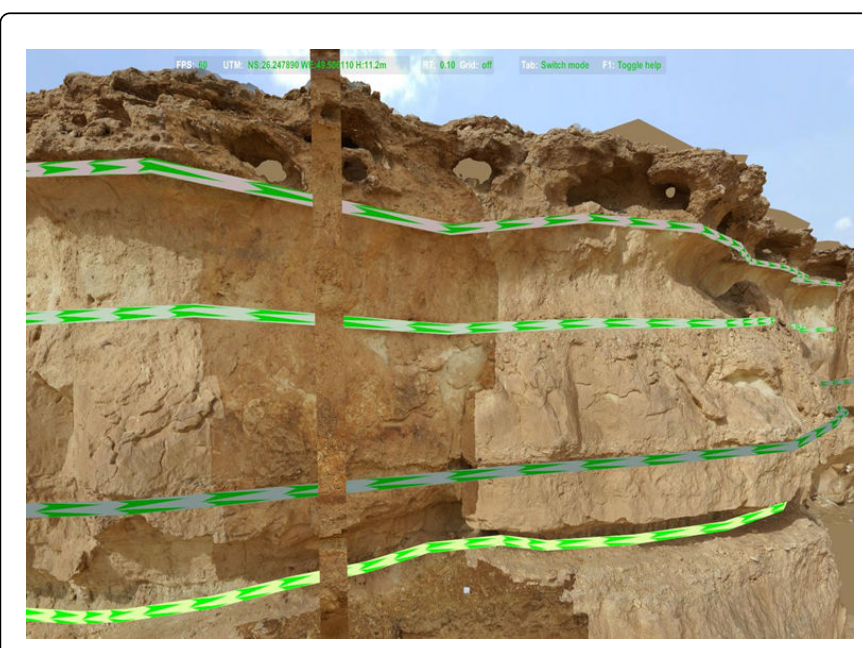

Figure 18: Geological toolbox offering quantitative outcrop analysis such as stratigraphic correlation and synthetic outcrop coring.

\section{Conclusion}

Photogrammetry in combination with drone-based remote sensing and application of these technologies in geology for studying and modeling large-scale geological outcrops appear to be an advanced solution in terms of cost, safety, accuracy, and efficiency. In this paper, we presented an integrated workflow using low-cost drone-based photogrammetry for the creation of a $3 \mathrm{D}$ geological model for the Wadi Dirab outcrop. The results of photogrammetric data processing using dedicated software, include a photo plan of the rocky outcrop, a textured point cloud, and a digital terrain model.

The results clearly show the advantages of using low-cost UAVs and cameras when collecting geological data. Cliff areas that were previously inaccessible by geologists can now be examined in reasonable detail without jeopardizing safety. Hence, lateral bed continuity of different facies could be traced that otherwise would be difficult to do in the field due to accessibility issues. A more complete 3D digital outcrop model also provides ongoing instantaneous access to the area without having to revisit the field.

\section{Acknowledgements}

Thanks to Saudi Aramco for granting permission to publish this work. We would like to thank Salem H. Shammari and Saeed S. Shahrani from Saudi Aramco for their contribution in conduction the field work. We would like to thank FalconViz staff for their support in conducting this study and operating their drones. We also would like to thank and appreciate the management of Dirab Motor Park in Riyadh for their support and permission to access their property.

\section{References}

1. Fallatah MI, Kerans C (2018) Stratigraphic evolution of the Late Jurassic Hanifa Formation along the Tuwaiq Escarpment, Saudi Arabia: Evidence for a carbonate ramp system. Sedimentary Geology 363: 152-180.

2. Hughes GW, Varol O, Al-Khalid M (2008) Late Oxfordian micropalaeontology, nannopalaeontology and palaeoenvironments of Saudi Arabia. GeoArabia 13: 15-46.

3. Vaslet D, Manivit J, Le Nindre YM, Brosse JM, Fourniguet J, et al. (1983) Explanatory Notes to the Geologic Map of the Wadi Ar Rayan Quadrangle, Sheet 23H, Kingdom of Saudi Arabia. Saudi Arabian Deputy Ministry for Mineral Resources, GM-63A, Geosciences Map, Jeddah, Saudi Arabia.

4. Manivit J, Pellaton C, Vaslet D, Le Nindre YM, Brosse JM, et al. (1985) Explanatory Notes to the Geologic Map of the Darma' Quadrangle, Sheet $24 \mathrm{H}$, Kingdom of Saudi Arabia. Saudi Arabian Deputy Ministry for Mineral Resources, GM-101C, Geosciences Map, Jeddah, Saudi Arabia.

5. Gradstein FM, Ogg JG, Schmitz MD, Ogg GM (2012) The Geologic Time Scale 2012. Elsevier, New York, USA.

6. Hughes GW (2004) Middle to Upper Jurassic Saudi Arabian carbonate petroleum reservoirs: biostratigraphy, micropaleontology, and paleoenvironments. GeoArabia 9: 79-114.

7. https://www.asprs.org/

8. Asit KB, Margaret RB (2008) Complete Dictionary of Scientific Biography. 